\title{
Optimization of lupine hydrolyzate separation
}

\author{
Jiř́ Pecha ${ }^{1, *}$, Jakub Husár ${ }^{1}$, Miloš Jelínek ${ }^{2}$, Lubomír Š́nek ${ }^{1}$, and Karel Kolomazník ${ }^{1}$ \\ ${ }^{1}$ Tomas Bata University in Zlín, Faculty of Applied Informatics, Regional Research Centre CEBIA-Tech, Nad Stráněmi 4511,760 05, \\ Zlín, Czech Republic \\ ${ }^{2}$ University of Hradec Králové, Faculty of Science, Department of Informatics, Rokitanského 62, 500 03, Hradec Králové, Czech \\ Republic
}

\begin{abstract}
Lupine hydrolyzate is a promising source of proteins. Hydrolysis of lupine flour was studied under various conditions and their influence on reaction mixture separation by means of filtration was assessed. A mathematical model describing separation process was suggested and verified. This model was used in further calculations and process simulations. It was shown, that the filtration largely depends on the molar mass distribution, respectively the degree of hydrolysis. In addition, an approach enabling optimizing filtration was presented. The time of filtration performed at optimal conditions was almost ten times decreased.
\end{abstract}

\section{Introduction}

The use of hydrolysis for the refining and isolation of valuable components of non-traditional protein sources such as lupine represents a technologically interesting and promising way of the processing of said feedstock [1-3]. For its industrial implementation, it is crucial to design a manufacturing process with regard to its maximal economic efficiency. The process-economic mathematical modelling is a very effective tool for achieving this goal. It not only allows finding suitable operating conditions corresponding to the economic optimum and thus evaluating the economic viability of the proposed technology, but is also an important basis for the design and development of the manufacturing equipment. [4]

The key step in industrial hydrolytic treatment of lupine flour is the separation of the soluble and insoluble phases of the reaction mixture. The presented paper focuses on the separation of said phases by means of filtration. A suitable model is derived, verified by experimental data and different technological conditions are compared from the view of reaction mixture separation. The comparison is facilitated by simulation calculations performed by the verified mathematical model of the process. In addition, an approach enabling optimizing filtration is presented.

\section{Quantitative description of separation}

From the practical point of view, the main task in the calculation of filtration is to estimate the time needed for the filtration in dependence on the available size of the filter device and the intensity of the driving force of filtration - the pressure difference before and after the filter cake, respectively the pressure gradient along the thickness of the filter cake. The available filtration time defines the required filter area to ensure its sufficient performance concerning the capacity of the entire production unit. This is very closely related to the production economy and the return on investment period; therefore, optimization of the production unit's filter node goes beyond mere process design. [5]

The average flow rate of the filtrate through the filter cake layer is proportional to the pressure difference, the relationship can be written as follows:

$d p=-\alpha \cdot \eta \cdot d h \cdot v_{F}$

where $d p$ denotes the pressure difference on the boundaries of the filter cake layer of thickness $d h, \alpha$ stands for the specific resistance of the filter cake, $\eta$ is the viscosity of the filtrate and $v_{F}$ is the mean velocity of the filtrate across the filter surface. [6]

For the mean filtrate velocity across the filter area:

$v_{F}=\frac{\dot{V}_{F}}{S}=\frac{1}{S} \frac{d V_{F}}{d \tau}$

where $S$ stands for the area of filtering device and $\dot{V}_{F}$ is the actual volume flow of filtrate through the filter cake layer. [6]

Furthermore, it should be pointed out that the total thickness of the filter cake is not constant but time dependent; it can be expressed as a function of the volume of filtrate passed through the filtration device. If the filtered suspension is homogeneous, we can assume that the total thickness of the filter cake is directly proportional to the amount of filtrate obtained, therefore:

$h(\tau)=k \cdot \frac{V_{F}(\tau)}{S}$

\footnotetext{
* Corresponding author: pecha@utb.cz
} 
We can express the constant of the proportions from (3) as follows:

$$
k=\frac{V_{K}}{V_{F}}
$$

where $V_{K}$ denotes the volume of the filter cake. [6]

It should be noted that if the concentration of the filtered suspension fluctuated, we could further express the rate constant $k$ as a function of the solids content in the filtered suspension. By a combination of the abovementioned equations for filtration through the filter cake and the filter layer itself, which must also be included in the calculation, we get a differential equation of filtration that can be written as follows:

$\frac{d \tau}{d V_{F}}=\frac{1}{\Delta p \cdot S}\left[\alpha \cdot \eta \cdot\left(k \frac{V_{F}}{S}+C\right)\right]$

The filter equation (5) is written for a given filter cake thickness, which is expressed by the amount of filtrate passed through the unit area, constant $C$ indicates the filter layer equivalent resistance and $\Delta p$ is the total pressure difference above the filter cake and below the filter layer. [6]

$$
\begin{aligned}
& \beta=\alpha \frac{V_{K}}{V_{F}}=\alpha \cdot k \\
& R=\alpha . \eta \cdot C
\end{aligned}
$$

After introducing substitutions (6) and (7) we obtain the resulting differential equation of the filtration:

$$
\frac{d \tau}{d V_{F}}=\frac{1}{\Delta p \cdot S}\left(\beta \cdot \eta \frac{V_{F}}{S}+R\right)
$$

By solving equation (8), assuming a constant pressure difference, we get relation (9), by means of which we can evaluate the experimental data and simulate and optimize the whole process. [6] Let us note that this relation is valid for filtration performed at constant pressure difference which is common but not the single option.

$$
\tau=\frac{V_{F}}{\Delta p \cdot S}\left(\beta \cdot \eta \frac{V_{F}}{2 S}+R\right)
$$

\section{Experimental measurement and data evaluation}

For filtration assays, the reaction mixture was prepared by a standard procedure, i.e. finely ground lupine flour was hydrolyzed in a $2 \%$ aqueous lactic acid solution, which is also the major hydrolysis catalyst present in the whey. The hydrolysis time was 6.5 hours and the reaction temperature was $90{ }^{\circ} \mathrm{C}$. Said reaction conditions are further referred to as Hydrolysis No.1. The reaction mixture was then filtered through a coarse filter cloth (mesh diameter approximately $0.3 \mathrm{~mm}$ ) and the resulting filtrate formed by the suspension was used for filtration tests at a constant pressure difference of $1.5 \mathrm{kPa}$ ensured by a vacuum pump. The low value of pressure difference was chosen due to the fact that the filter cake is compressible.

The vacuum was maintained at the selected value by an electronically controlled vacuum pump and the amount of filtrate was continuously recorded. The standard laboratory filter paper KA-1 was used as the filtration layer. It should be noted that in some filtration tests, the addition of diatomaceous earth was used, both for the creation of the base of the filtration layer and as an filter aid. The suspension was in all cases heated to 50 ${ }^{\circ} \mathrm{C}$ prior to filtration.

A software was programmed for the evaluation of experimental data, enabling further comparison of the experimental data with the calculations according to the predicted model. Figure 1 shows the fit of the experimental data by the linearized form of a mathematical model of filtration. As shown in the figure, there is a good agreement of the experimental data with the model, even in the case if the resistance of the filter layer is neglected. The data shown were collected from the filtration test, when the addition of fine diatomaceous earth was used to facilitate filtration.

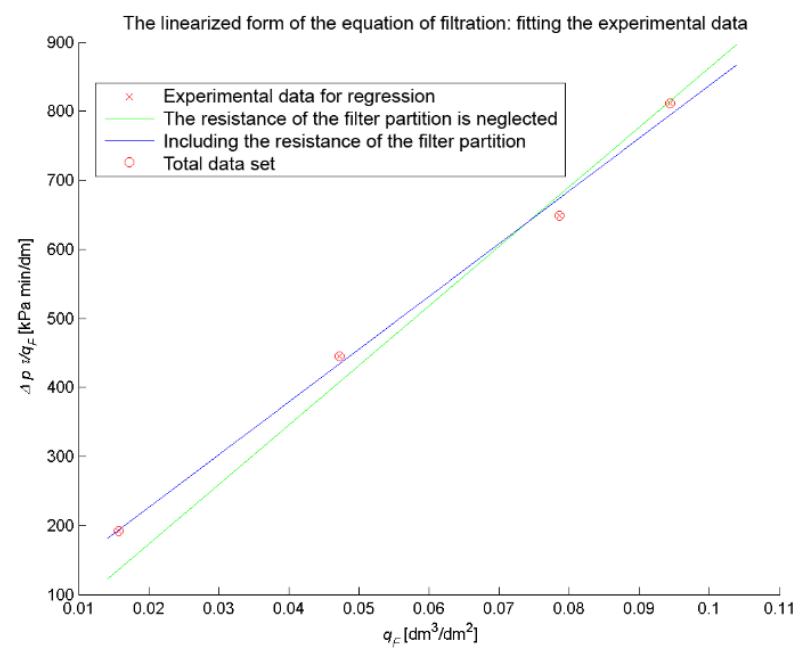

Fig. 1. Experimental data evaluation - Linearized form of filtration equation - Hydrolysis No.1.

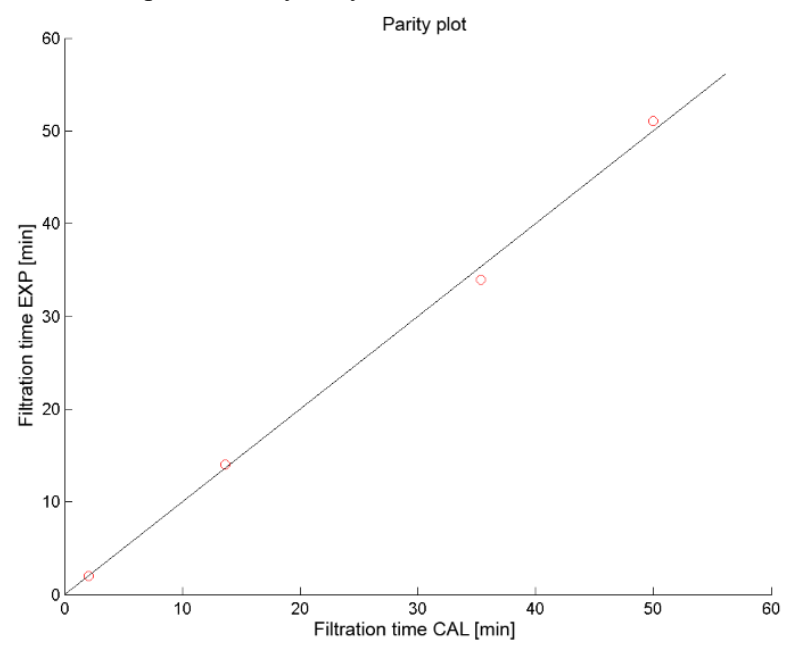

Fig. 2. Parity plot - Comparison of experimentally determined filtration time (EXP) with filter time estimated by mathematical model (CAL) - Hydrolysis No.1. 
Comparison of the calculated filtration time based on a mathematical model with the experimentally determined filtration time - parity plot - is depicted in Figure 2. As can be seen from the comparison, the chosen mathematical model very well describes the experimental data, which is a prerequisite for real simulation calculations of filtration time and its subsequent optimization.

Table 1 compares the evaluated filtration characteristics of the reaction mixture suspension for the filtration variants tested. The values presented in the table show that the filter layer resistance can be neglected and also that the resistance of the filter cake is considerably high. It should be noted that the clarity of the filtrate obtained after addition of diatomaceous earth was higher, but so was the measured filter cake resistance. The lowest filter cake resistance was measured using a coarse non-woven fabric; the clarity of the filtrate was naturally the worst. However, for use in the food industry, this property of the filtrate is acceptable.

Table 1. Filtration data - Hydrolysis No.1

\begin{tabular}{|c|c|c|}
\hline $\begin{array}{c}\text { Filtration type - } \\
\text { filter layer, auxiliary } \\
\text { substances }\end{array}$ & $\begin{array}{c}\text { Filter cake } \\
\text { resistance } \\
{\left[\mathrm{kPa} \cdot \mathrm{min} . \mathrm{dm}^{-2}\right]}\end{array}$ & $\begin{array}{c}\text { Filter layer } \\
\text { resistance } \\
{\left[\mathrm{kPa} \cdot \mathrm{min} \cdot \mathrm{dm}^{-1}\right]}\end{array}$ \\
\hline Filter paper KA-1 & 11794 & 205 \\
\hline $\begin{array}{c}\text { Coarse non-woven } \\
\text { fabric }\end{array}$ & 1579 & 0 \\
\hline $\begin{array}{l}\text { Filter paper KA-1, } \\
\text { diatomaceous earth }\end{array}$ & 19030 & 0 \\
\hline
\end{tabular}

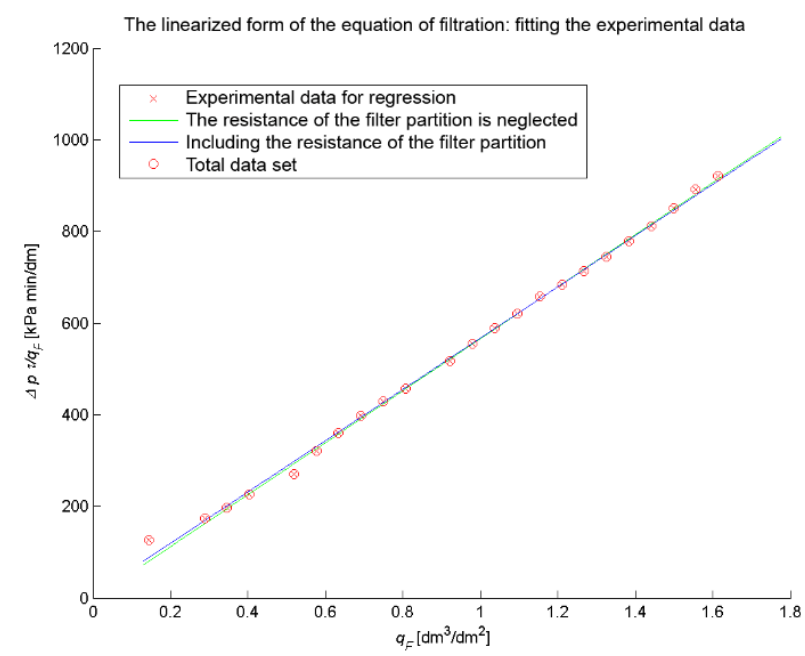

Fig. 3. Experimental data evaluation - Linearized form of the filtration equation - Hydrolysis No.2.

The reaction mixture from the pressure hydrolysis (further referred to as Hydrolysis No.2) of lupine flour $\left(140{ }^{\circ} \mathrm{C}, 2\right.$ wt. $\%$ lactic acid solution, the concentration of solids in the lupine flour mixture $4.8 \mathrm{wt} . \%$ ) was mixed with the filter medium - diatomaceous earth. Diatomaceous earth was dosed at a concentration of 2.3 wt.\% to the filtered suspension. The suspension was filtered through a laboratory pressure filter, with a commercial filter cloth used in industrial filter presses as a filter layer.

Figure 3 shows the experimental data fitted by the linearized form of the mathematical model of filtration. As shown in the figure, the agreement of the experimental data with the model is excellent, even if we neglect the resistance of the filter layer.

Figure 4 presents comparison of the calculated filtration time based on the mathematical model with the experimentally determined filtration time in the standard form of parity plot. Even this figure clearly demonstrates suitability of the model for quantitative description of the investigated process.

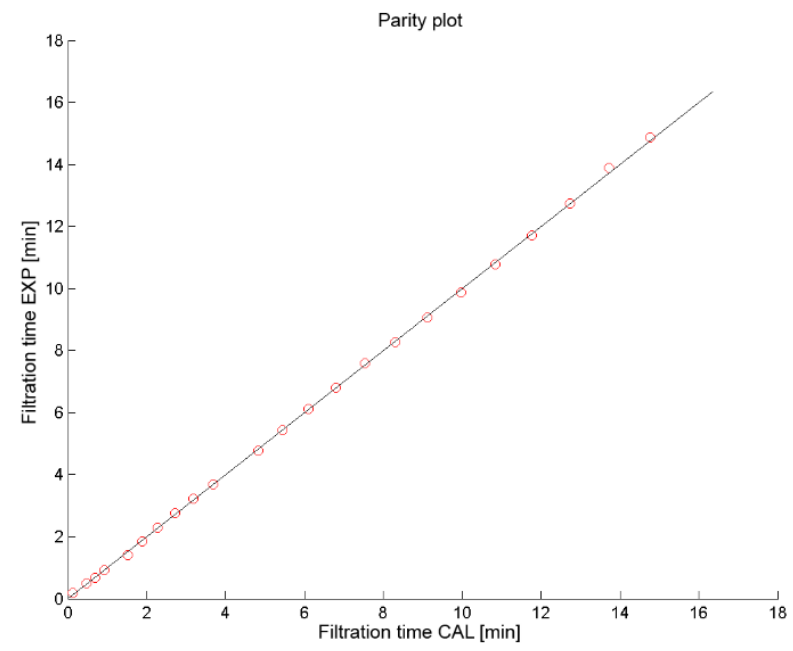

Fig. 4. Parity plot - Comparison of experimentally determined filtration time (EXP) with filter time estimated by mathematical model (CAL) - Hydrolysis No.2.

The evaluated filtration characteristics of the reaction mixture suspension are summarized in Table 2 . The values show that the filter layer resistance can be neglected. A clear filtrate was obtained, which, for example, could not be achieved by filtration through a coarse fabric, although the presence of fine suspension particles is acceptable in the food industry. A comparison of the data in Tables 1 and 2 shows that under similar conditions (addition of diatomaceous earth, high clarity of the filtrate, temperature of the filtered suspension) the resistance of the filter cake obtained after hydrolysis at $90{ }^{\circ} \mathrm{C}$ is almost 17 times higher than that of the hydrolysis carried out at a temperature of $140^{\circ} \mathrm{C}$. By using a non-woven fabric, we obtain similar values for both reaction temperatures of hydrolysis, but the quality of the filtrate differs in its clarity, and in particular, the used pressure difference during filtration, which fundamentally affects the filtration rate. The pressure difference was $1.5 \mathrm{kPa}$ in case of Hydrolysis No. $1\left(90^{\circ} \mathrm{C}\right)$ and $100 \mathrm{kPa}$ in case of Hydrolysis No.2 $\left(140^{\circ} \mathrm{C}\right)$.

Table 2. Filtration data - Hydrolysis No.2.

\begin{tabular}{|c|c|c|}
\hline $\begin{array}{c}\text { Filtration type - } \\
\text { filter layer, auxiliary } \\
\text { substances }\end{array}$ & $\begin{array}{c}\text { Filter cake } \\
\text { resistance } \\
{\left[\mathrm{kPa} \cdot \mathrm{min} \cdot \mathrm{dm}^{-2}\right]}\end{array}$ & $\begin{array}{c}\text { Filter layer } \\
\text { resistance } \\
{\left[\mathrm{kPa} \cdot \mathrm{min}_{\mathrm{dm}} \mathrm{dm}^{-1}\right]}\end{array}$ \\
\hline $\begin{array}{c}\text { Filter paper KA-1, } \\
\text { diatomaceous earth }\end{array}$ & 1133.5 & 0 \\
\hline
\end{tabular}




\section{Simulation and optimization}

The proposed model was used for simulation and optimization calculations in order to assess the feasibility of filtration and its optimal course.

Figure 5 shows filtration simulation of a $5 \mathrm{~m}^{3}$ of the reaction mixture through a $10 \mathrm{~m}^{2}$ filter. The maintenance time was set to 20 minutes for all simulations. The filtration parameters correspond to the hydrolysis of lupine flour at $90^{\circ} \mathrm{C}$ through a coarse non-woven fabric. It can be seen from the simulation that by optimization of the filtration process the filtration time can be reduced to less than 1500 minutes (25 hours). For larger industrial scale it would be necessary to further reduce the time by enlarging the filter area.

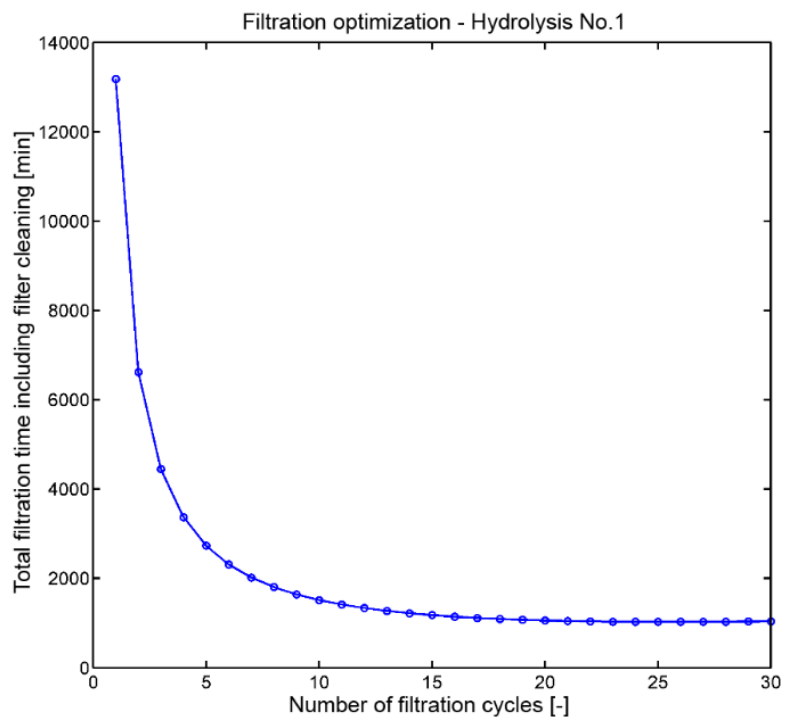

Fig. 5. The simulation and optimization of the filtration Hydrolysis No.1.

In comparison, the reaction mixture hydrolyzed at $140{ }^{\circ} \mathrm{C}$ can be filtered using an identical filter with $5 \mathrm{~m}^{3}$ of the reaction mixture in less than 2 hours under optimal process configuration, as can be seen in Figure 6 . The difference between the two filtrations is considerable. In this case, it is assumed that diatomaceous earth is dosed, also the pressure difference is higher compared to the pressure difference in the filtration of the reaction mixture from the hydrolysis conducted at $90{ }^{\circ} \mathrm{C}$. However, this difference is based on the experimental observation that in lower temperature hydrolysis the increase in the pressure difference during filtration had a negative effect on the filtration rate due to the compressibility of the filter cake.

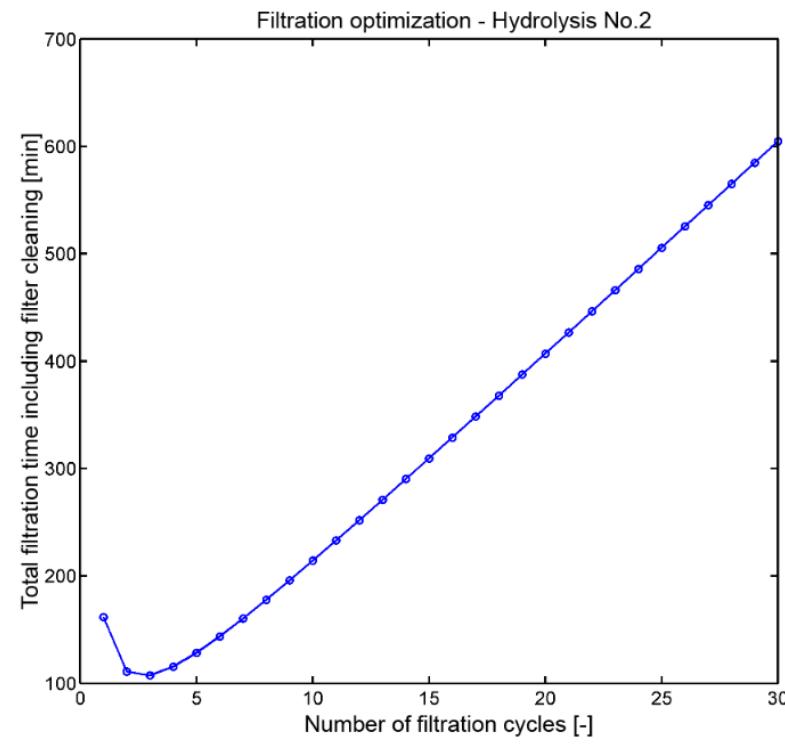

Fig. 6. The simulation and optimization of the filtration Hydrolysis No.2.

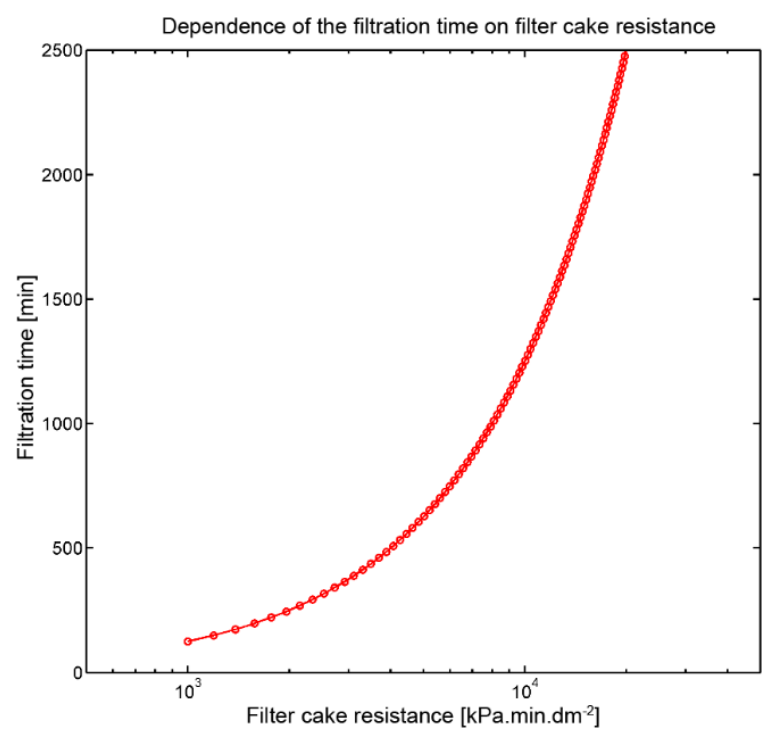

Fig. 7. Dependence of the filtration time on filter cake resistance.

The industrial feasibility of filtration on a given filter is determined by the resistance of the filter cake, which varies considerably according to the hydrolysis reaction conditions used. This dependence is shown in Figure 7 on the logarithmic scale. From the figure, it is possible to determine the required resistance of the filter cake to provide an acceptable filtration time on a particular filter. 


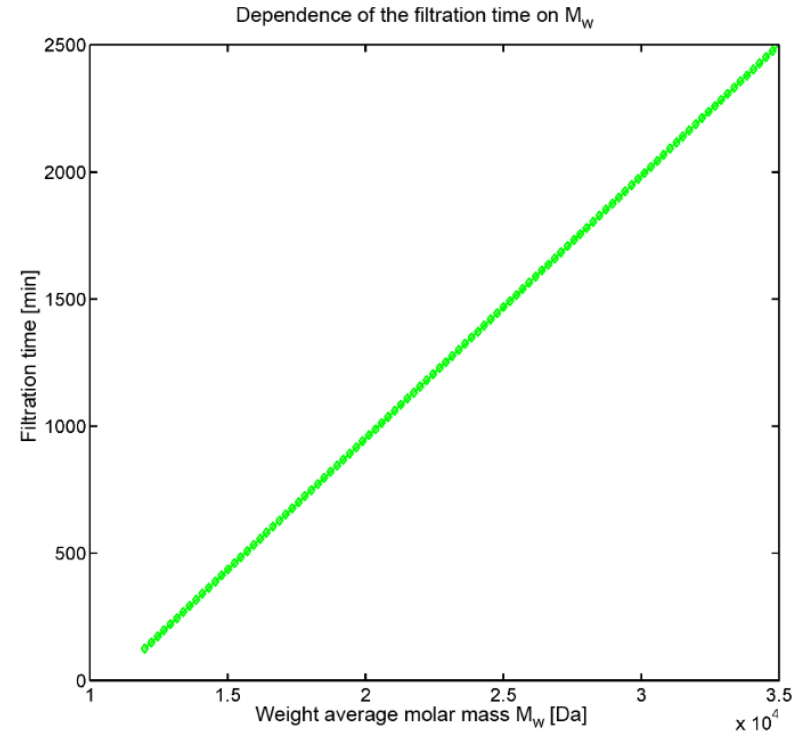

Fig. 8. Dependence of filtration time on weight average molar mass of liquid phase reaction mixture.

The measurement of the molar mass distribution performed by SEC method showed that the hydrolyzate prepared at $90^{\circ} \mathrm{C}$ had a weight average molecular mass of $34 \mathrm{kDa}$, while the weight average molecular mass of hydrolyzate prepared at $140{ }^{\circ} \mathrm{C}$ was $14 \mathrm{kDa}$. If we assume a linear dependence between the molar mass and the resistance of the filter cake, we can plot the dependence of the filtration time on the average molar mass similarly as in the previous case the dependence of the filtration time on the resistance of the filter cake (see Figure 8).

Thus, by means of Figures 7 and 8, we can estimate the degree of hydrolysis that is necessary to achieve for an industrially feasible separation of the solid and liquid phases of the reaction mixture in the hydrolysis of lupine flour.

\section{Conclusion}

It follows from the presented measurements and calculations that increasing the reaction temperature leads to substantial simplification of the separation of the liquid and solid phases by filtration which is caused by the decreasing of the lupine hydrolysate average molecular weight.

The chosen model was successfully verified by experimental data and further used for process simulation and optimization. It was shown that it is possible to decrease almost ten times the time necessary for filtration in case the process is lead at optimal conditions whose determination was presented.

Simulation calculations make it possible to estimate the required degree of hydrolysis, expressed by the weight average molar mass of the hydrolyzate, i.e. the liquid phase of the reaction mixture, which ensures acceptable filtration time on the available equipment.

The article also summarizes the filtration characteristics needed for the simulation calculations and design of a real separation device.
This work was supported by the Ministry of Education, Youth and Sports of the Czech Republic within the National Sustainability Programme project No. LO1303 (MSMT- 7778/2014) and by the European Regional Development Fund under the project CEBIA- Tech No. CZ.1.05/2.1.00/03.0089 and by project gama of the Technology Agency of the Czech Republic No. TG02010020 Center for Transfer of Biomedical Technologies - PoC and also by the internal project No. RVO/CEBIA/2019/003.

\section{References}

1. K. Kolomazník, J. Jelínek, Š. Hubálovský, and M. Jelínek, "Food supplement and process for preparing thereof" (2013) (czech patent 303837)

2. M. Jelínek, J. Pecha, J. Jelínek, Š. Hubálovský, and K. Kolomazník, "A fibre food supplement” (2017) (czech utility model 30718)

3. M. Jelínek, J. Pecha, J. Jelínek, Š. Hubálovský, and K. Kolomazník, "A hydrolyzed food supplement" (2017) (czech utility model 30719)

4. S. Hubalovsky, J. Jelinek, M. Jelinek, K. Kolomazník, Conference; 5th, Recent researches in chemistry, biology, environment and culture, 132137 (2011).

5. J. Horák, J. Pašek, Návrh průmyslových chemických reaktori z laboratornich dat. 1. vyd. Praha: Státni nakladatelství technické literatury (1980) (czech book)

6. V. Míka, J. Vlček, L. Neužil, Chemickoinženýrské výpočty I., (1996) (czech book) 